\title{
The Combination of Butyl Para-Aminobenzoate and lodoform as a Secondary Prevention of Dry Socket: A Systematic Review
}

\author{
Pipiet Okti Kusumastiwi*, Julita Hendrartini, Iwan Dwiprahasto \\ Doctoral Programme, Faculty of Medicine, Public Health and Nursing, Universitas Gadjah Mada, Yogyakarta, Indonesia
}

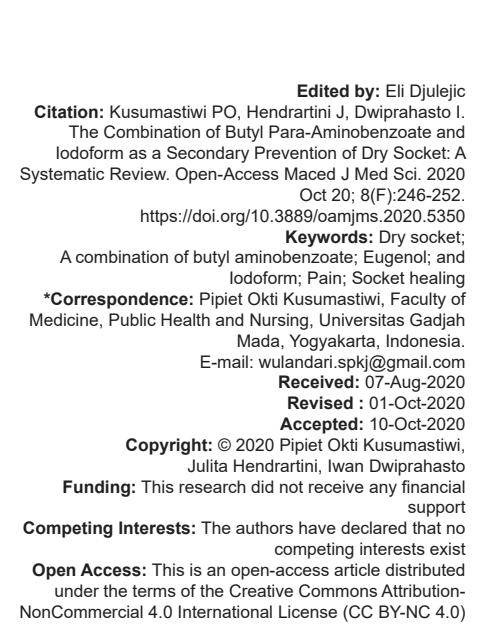

\section{Introduction}

Dry socket is a post-tooth extraction complication that most commonly occurs [1] and is most widely studied [2]. Some other terminologies of dry socket include alveolar osteitis, fibrinolytic alveolitis, alveolitis sicca dolorosa, post-operative alveolitis, alveolalgia, septic socket, necrotic socket, localized osteomyelitis, delayed extraction wound healing, and localized osteitis. Crawford began to use the term "dry socket" in 1896 [3]. The incidence of dry socket in post-simple tooth extraction and surgical tooth extraction varies greatly. It ranges from $1 \%$ to $70 \%$ and more frequently occurs in the post-lower third molar extraction [3], [4].

The primary etiology of dry socket is an increase in local fibrinolytic activity. The increase can cause loss of intra-alveolar blood clots after tooth extraction [5]. The fibrinolysis is the result of activation of the plasminogen pathway, which can be achieved through the substance of a direct (physiological) or indirect (non-physiological) activator. The activators are released immediately after trauma to the alveolar bone cells and are not directly secreted by bacteria [6]. However, the exact etiology of dry sockets explained above is not yet well understood [7], [8].

Many risk factors are associated with dry sockets, such as extraction trauma and extraction difficulties, mandibular third molar extraction, systemic disease, bacterial infection, excessive irrigation or curettage, local anesthesia with vasoconstrictors, and bone or root fragments remaining in socket [6]. Patients with dry sockets usually experience persistent pain around the socket and the location of the operation after tooth extraction. These symptoms usually appear two to four quickly disappear even after consuming analgesics and often halitosis [9]. Concerning these signs and symptoms, the primary purpose of dry socket treatment is to relieve pain and stimulate the healing process of open bone, especially by palliative care.

Since the dry socket is the most common complication at post-tooth extraction, many researchers 
work to find a method for primary prevention of dry socket. However, it remains controversial because there is no single method that can be universally accepted [6]. Therefore, secondary prevention of this case is still needed to prevent the continued effects of dry socket (a decrease in quality of life due to pain, discomfort in the mouth, and halitosis) and other complications resulting from inadequate dry socket treatments such as trigeminal neuralgia [10], neuritis [11], and foreign body reactions [12].

Dry socket treatments are divided into two groups, namely, undressing and dressing. The use of dressings for dry socket treatment is still controversial because there have been no studies explicitly identifying the assessment toward the occurrence of potential side effects and tissue damage arising from its placement into the socket [9].

One of the dressings that have been widely used in dry socket treatment and are often mentioned in the literature is an ingredient with a combination of butyl para-aminobenzoate and iodoform. Literature states that the presence of the dressing material in the socket causes foreign body reaction, delayed healing, and prolonged pain (up to 14 days) [13].

This study aims to compare the result of dry socket treatment using a combination of butyl paraaminobenzoate and iodoform and other treatments for a dry socket to relieve pain and stimulate socket healing.

\section{Materials and Methods}

This systematic study was constructed by following the guidelines for preferred reporting items for systematic reviews and meta-analysis [14]. The patient, intervention, comparison, outcome, and study (PICOS) framework (population, intervention, control, results, and study design) was designed to identify studies and use their elements as the main selection criteria [15].

\section{Eligibility criteria}

This study aims to conduct a literature review comparing the result of dry socket treatment using a combination of butyl para-aminobenzoate and iodoform to other dry socket treatments. The concept of was arranged as follows:

- $\quad \mathrm{P}$ (patient): Patients with dry socket after tooth extraction

- I (intervention): Dressing with ingredients containing butyl para-aminobenzoate and iodoform

- $\quad$ C (comparison ): Other dry socket treatments

- $\quad \mathrm{O}$ (outcome): Reduction of pain and healing

- $\quad S$ (study): Clinical trial with or without a placebo comparison.
Inclusion criteria included clinical research with a minimum of 10 patients as respondents published in English from 2009 to 2019. Meanwhile, exclusion criteria included case reports and systematic reviews. The characteristics of the patients in this study were all ages, both men and women who experienced dry socket after tooth extraction, either a simple extraction or surgical extraction.

\section{Information sources}

The search was conducted in the electronic databases, such as PubMed (including Medline), Google Scholar, and Clinical Key.

\section{Search strategy}

Electronic search in the PubMed database, Google Scholar, and Clinical Key was carried out using medical terms as the subject title and search algorithms with key terms for the title and abstract, for instance, "alvogyl" or "butyl para-aminobenzoate + iodoform" and "dry socket" or "fibrinolytic alveolitis" or "sicca dolorosa alveolitis" or "postoperative alveolitis" or "alveolalgia" or "septic socket" or "necrotic socket" or "localized osteomyelitis" or "localized osteitis" or "delayed wound healing of extraction."

\section{Study selection}

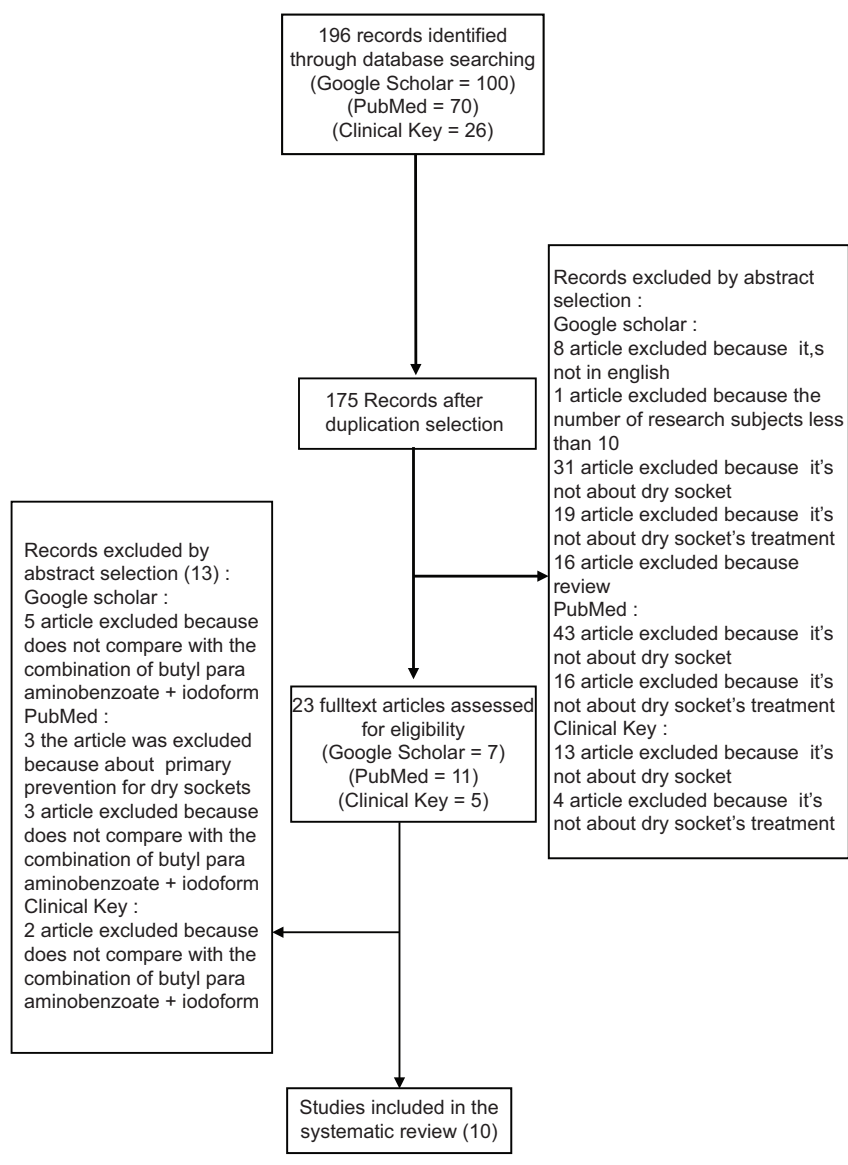




\section{Outcomes and prioritization}

The outcome reviewed in this study was pain reduction and socket healing. The prioritized outcome was pain reduction because the main disturbing symptom to the dry socket is pain.

\section{Risk of bias in individual studies}

The risk of bias was assessed based on the guidelines of the Cochrane Collaboration [16], [17]. The guidelines are such as sequence generation, allocation concealment, blinding of the participant, blinding of care provider, the incomplete outcome of data addressed, and free from funding sources of bias.

\section{Results}

In the result of the initial search, it was obtained 196 articles. On the process of duplication reduction, 175 articles were obtained. At the abstract assessment stage, 152 articles were excluded because they were irrelevant. Full-text assessment was carried out on 23 articles, and then, 10 articles were excluded because they did not compare dry socket treatment with a combination of butyl para-aminobenzoate and iodoform. The other three articles were also excluded because medicament material was used to prevent dry socket. Therefore, 10 articles were reviewed in this systematic study.

Alternative treatments found were such as zinc oxide eugenol (ZOE), chlorhexidine digluconate gel, hyaluronic acid with or without aminocaproic, a combination of polymyxin B sulfate, tyrothricin, neomycin sulfate, tetracaine hydrochloride, freeze-dried pledget containing acemannan hydrogel, plasma rich in growth factors (PRGF), and low-level laser therapy, Er:Cr:YSGG, and laser diodes. Some ingredients, such as ZOE and chlorhexidine digluconate gel, were found in several journals.

About the review conduction, the majority of tests had a high risk of bias. All articles are unclear on the sequence generation process. There was 1 article [18] which had high risk in allocation concealment because randomization was carried out by research staff, and the other two articles [19], [20] had a low risk because it used randomization with tables as well as systematic random sampling methods. No articles were explaining how to conduct participant blinding, and only two articles carried out blinding of the clinical examination [18], [20]. Furthermore, one article explained about the training provided to patients on how to measure visual analog scale (VAS) and calibrating clinical examinations performed by dentists with $\mathrm{P}$ score $=0.78$ [18].

On the other hand, there was one article stating that the research obtained funding sources that had a potential of risk of bias in the result of the research [18] and that the article was included in the category of having a high risk of bias. In terms of the financial aspect, two articles mentioned funding sources and thank you note that had no risk of bias [19], [20] while the other article mentioned that it did not receive financial support [20]. In addition, five articles did not explain financial sources [16], [17], [18], [19], [20] (Table 1).

\section{Dry socket diagnosis}

The diagnosis was explained by seven articles [7], [8], [10], [11], [18], [19], [20]. All of them used pain as a primary indication for the diagnosis of a dry socket. There were three articles [19], [20] referring to the definition of Blum, 2002 [9], as the diagnosis, for instance, pain and damaged blood clot in the socket, along with or without halitosis. The other indication used for the diagnosis was the open bone on the socket.

\section{Stage before application}

Irrigation with sterile saline was applied to all groups in the articles reviewed. All irrigations were carried out under local infiltration anesthesia. There were two articles [17], [19] stating to avoid curettage in the socket while another article [20] conducted curates after anesthesia. Furthermore, medication application varied greatly. One of the articles [18] explained that it did not give antibiotics to all study subjects, while the other two articles [16], [20] did not include subjects who received antibiotics after extraction. Article [17] mentioned giving amoxicillin and metronidazole as antibiotics to all study subjects. Another article [18] gave tablets containing diclofenac sodium and paracetamol to all study subjects, while the other article gave ibuprofen.

Table 1: Risk of bias

\begin{tabular}{|c|c|c|c|c|c|c|}
\hline Study & Sequence generation & Allocation concealment & Blinding of participant & Blinding of care provider & Incomplete outcome data addressed & Free from sources funding bias \\
\hline 20 & Unclear & High risk & High risk & High risk & Low risk & High risk \\
\hline 21 & Unclear & Low risk & High risk & High risk & High risk & Low risk \\
\hline 22 & Unclear & Unclear & High risk & High risk & High risk & Unclear \\
\hline 23 & Unclear & Unclear & High risk & High risk & High risk & Low risk \\
\hline 24 & Unclear & Low risk & Unclear & Low risk & High risk & Unclear \\
\hline 25 & Unclear & Unclear & Unclear & Unclear & High risk & Low risk \\
\hline 26 & Unclear & Unclear & Unclear & Unclear & High risk & Unclear \\
\hline 7 & Unclear & Unclear & Unclear & Unclear & High risk & Unclear \\
\hline 28 & Unclear & Unclear & Unclear & Unclear & High risk & Unclear \\
\hline 29 & Unclear & Unclear & Unclear & Unclear & High risk & Unclear \\
\hline
\end{tabular}




\section{Observation time}

Table 2:

The observation time varied, as shown in

\section{Table 2: Observation time}

\begin{tabular}{ll}
\hline No. of article & Observation time \\
\hline 16 & On the $3^{\text {rd }}$ day $\left(+-1\right.$ day) and the $7^{\text {th }}$ day $(+-1$ day) \\
17 & $\begin{array}{l}\text { Patients were asked to note pain in the morning, after } 6 \mathrm{~h} \text { and after } \\
12 \mathrm{~h} \text {, for } 3 \text { days }\end{array}$ \\
18 & $\begin{array}{l}\text { The pain was checked every morning for } 1 \text { week after the initial } \\
\text { debridement using visual analog scale. Clinical examination of signs and } \\
\text { symptoms is examined at the time of diagnosis, } 3 \text { days after diagnosis, }\end{array}$ \\
& $\begin{array}{l}\text { and } 7 \text { days after diagnosis } \\
\text { The pain was examined on the } 3^{\text {rd }}, 4^{\text {th }} \text {, and } 5^{\text {th }} \text { day. Healing was } \\
\text { examined on the } 4^{\text {th }}, 7^{\text {th }}, 10^{\text {th }} \text {, and } 14^{\text {th }} \text { day }\end{array}$ \\
20 & $\begin{array}{l}\text { Pain and healing were examined } 5 \text { min, } 30 \text { min, } 1 \mathrm{~h}, 1^{\text {st }}, 2^{\text {nd }}, 3^{\text {rd }}, 5^{\text {th }}, 7^{\text {th }}, \\
\text { and } 10^{\text {th }} \text { days after medicament application } \\
\text { Pain and healing were examined on the } 3^{\text {rd }}, 5^{\text {th }}, 7^{\text {th }}, \text { and } 10^{\text {th }} \text { day }\end{array}$ \\
&
\end{tabular}

\section{The measured outcome}

1. Pain

Pain is a significant symptom of dry socket pathology. Therefore, all articles analyzed the pain reduction and compared to other various treatment alternatives. In terms of assessing pain intensity, VAS was used to identify patients' intensity of pain, with a range of scores between 0 (no pain) and 10 (unbearable massive pain) [15], [16], [19], [20]. Two articles [18], [20] used VAS by asking the patients the intensity of pain, with a score between 0 and 10 [19], [20], and categorized them into three criteria, such as mild (the VAS score 1-4), average (the VAS score 5--7), and high (the VAS score 8-10). One article [19] used the criteria of the dose of analgesic needed, namely, diclofenac sodium, with a score of 0 (no pain and no analgesia are needed); 1-3 (mild pain and when one tablet of $50 \mathrm{mg}$ of diclofenac sodium per day is consumed); 4-6 (moderate pain and when two tablets of $50 \mathrm{mg}$ of diclofenac sodium per day are consumed); and 7-10 (severe pain and when more than two tablets of $50 \mathrm{mg}$ of diclofenac sodium per day are consumed). Besides that, another article [13] used the Wong-Baker VAS.

\section{Healing}

The alveolar mucosa is one of the most commonly used indications to assess dry socket healing. It is more objective than pain reduction. However, four articles [12], [13], [17], [20] reviewed did not conduct an assessment of the healing process.

Various indicators of healing used in the article are such as: The exposed alveolar bone, halitosis, and dysgeusia [18]; halitosis, empty sockets, redness around the socket, and mouth discomfort [20]; open bones, no granulation tissue, and tenderness [18]; empty sockets, open bones, and redness around the socket [18]; sockets are covered by granulation tissue [20]; the spread of pain, swollen lymphonodi, redness, and halitosis [19].

One of the articles [10] added measured outcomes; for example, the amount of dressing required until the socket is cured. The other outcome was the complication of a dry socket that was the slow healing process, abscesses, osteomyelitis, infection, and reactions due to the foreign body. Meanwhile, the other article [18] added measured outcome, namely, sensitivity to gentle probing on the socket.

\section{Discussion}

\section{Pain reduction}

The observation time varied considerably among the articles reviewed. Article [19] using VAS indicator, which differs from the other. The indicator used the amount of diclofenac sodium consumed by the patient to relieve pain. Moreover, the comparison between a combination of butyl para-aminobenzoate and iodoform and other treatments also varied.

Compared to the PGRF, there is no significant difference in the reduction of pain at all observation times. Similar results were identified when the combination of butyl para-aminobenzoate and iodoform is compared to freeze-dried pledget containing acemannan hydrogel and the radiation of Er:Cr:YSGG.

There is a study in one article [18] with the most detailed observation time, which is gradually examined at the $5^{\text {th }} \mathrm{min}, 30^{\text {th }} \mathrm{min}, 1^{\text {st }} \mathrm{h}, 1^{\text {st }}$ day, $2^{\text {nd }}$ day, $3^{\text {rd }}$ day, $5^{\text {th }}$ day, $7^{\text {th }}$ day, and $10^{\text {th }}$ day after medicament application. Therefore, it can be seen that the average of the fastest time to start a pain reduction using the combination between butyl para-aminobenzoate and iodoform is at the $7.35^{\text {th }} \mathrm{min}$. The time record is faster than other treatments, which are at the $17.23^{\text {rd }}$ min for the combination between polymyxin B sulfate, tyrothricin, neomycin sulfate, tetracaine hydrochloride, and at the $25.02^{\text {nd }}$ min for ZOE. The shortest average time for overall pain relief is achieved by a combination between polymyxin $B$ sulfate and tyrothricin, which is on the $4.85^{\text {th }}$ day. In contrast, the combination of butyl paraaminobenzoate and iodoform takes 64.7 days, and ZOE takes 8.64 days. The comparison of the combination between butyl para-aminobenzoate and iodoform and ZOE is examined by two articles [17], [18] with the different results. One article [18] states that there is a significant difference in the pain reduction between the group of a combination of butyl para-aminobenzoate and iodoform and the group of ZOE. It can be seen based on the score of VAS in the group of combination butyl para-aminobenzoate and iodoform, which is lower than that of the ZOE group. Pain intensity decreases more rapidly in the group of combination between butyl para-aminobenzoate and iodoform compared to ZOE. The average time needed to relieve the whole pain is shorter in the group of a combination of butyl para-aminobenzoate and iodoform compared to the ZOE group. Other results are shown by other articles 
[17] stating that the VAS score in the $30^{\text {th }}$ min of the examination after medicament application, on the $7^{\text {th }}$ day and the $10^{\text {th }}$ day was significantly lower in the ZOE group compared to the group of combination between butyl para-aminobenzoate and iodoform.

The combination of butyl para-aminobenzoate and iodoform is proven to be better in relieving pain compared to low-power red laser and low-power infrared laser (the first $6^{\text {th }} \mathrm{h}$ and $12^{\text {th }} \mathrm{h}$ after the observation on the $1^{\text {st }}$ day, and the $6^{\text {th }} \mathrm{h}$ after the observation on the $2^{\text {nd }}$ day). However, on the $12^{\text {th }} \mathrm{h}$ after the observation on the $2^{\text {nd }}$ day and the $3^{\text {rd }}$ day, the VAS score is lower in the low-power red laser group compared to the group of the combination between butyl para-aminobenzoate and iodoform [19] groups. A similar result appears in another article [20], where the most drastic pain reduction is showed in the low-level laser therapy group, compared to the group of the combination between butyl paraaminobenzoate and iodoform on the observation on the $3^{\text {rd }}$ day and the $7^{\text {th }}$ day. The highest pain intensity in dry socket appears between 48 and $72 \mathrm{~h}$ after the tooth extraction [18]. It can be concluded that lowpower red laser and low-level laser therapy are more effective in controlling pain as it produces significant pain remission ranging from the $2^{\text {nd }}$ and the $3^{\text {rd }}$ day after the tooth extraction.

Furthermore, another laser studied was a diode laser. The result showed that there was a significant difference in the pain reduction between the group of the combination between butyl para-aminobenzoate and iodoform and the group of diode laser on the observation on the $3^{\text {rd }}, 4^{\text {th }}$, and $5^{\text {th }}$ day in which the group of diode laser showed a better result.

On the other comparison, the combination of butyl para-aminobenzoate and iodoform is revealed to be better in reducing pain than the chlorhexidine digluconate gel [16], [17]. One of the articles [16] shows that there is a significant difference in pain reduction between the two groups, on the $2^{\text {nd }}$ and the $4^{\text {th }}$ day, where the combination of butyl para-aminobenzoate and iodoform is proven to be more effective in reducing pain. In the result of the research presented [17], it revealed that no research subject experienced severe pain starting from the $2^{\text {nd }}$ day on the group of a combination of butyl para-aminobenzoate and iodoform. Meanwhile, in the group of chlorhexidine digluconate gel, there were still $64 \%$ of the study subjects experiencing severe pain on the $2^{\text {nd }}$ day and $21.6 \%$ were on the $3^{\text {rd }}$ day.

The different result appears in one article [14], which compared between the group of hyaluronic acid with or without aminocaproic and the group of the combination of butyl para-aminobenzoate and iodoform. On the $3^{\text {rd }}, 4^{\text {th }}$, and $5^{\text {th }}$ day of the examination, the pain reduction was shown better in hyaluronic acid than the group of the combination between butyl para-aminobenzoate and iodoform. This significant difference was statistically measured. The level of pain is almost similar between the group, which only received hyaluronic acid and the group which was additionally treated with aminocaproic acid.

\section{Healing}

As the indicators of the healing process vary, the comparison of the outcomes is relatively difficult to carry. The healing process of alveolar mucosa in the group of the combination between butyl paraaminobenzoate and iodoform is shown to be better, both in the indicator of time required for covering the socket by granulation tissue and in the number of complications. A clinical indication of the healing used is the empty socket, open bone, and red marks around the socket [12], [13].

The group of the combination between polymyxin B sulfate, tyrothricin, neomycin sulfate, and tetracaine hydrochloride is proved to be better in wound healing compared to the group of the combination between butyl para-aminobenzoate and iodoform, both in the indicator of the empty socket, exposed bone, as well as the red marks around the socket [13].

The comparison between the group of the combination between butyl para-aminobenzoate and iodoform with freeze-dried pledget containing acemannan hydrogel, and the group of low-level laser therapy proves that the best healing process on the $3^{\text {rd }}$ day was shown in the group of low-level laser therapy with the healing indicators such as the empty socket and red marks around the socket (all patients recovered from the empty sockets, and only $3 \%$ of them still experienced red marks around the socket). Meanwhile, in terms of the exposed bone, there are two groups with the best healing process, namely, the freeze-dried pledget group containing acemannan hydrogel where it showed $8.6 \%$ of patients recovering from the open bone, and the group of low-level laser therapy, where it showed that only $1 \%$ out of $12.5 \%$ of patients still experienced the open bone [20]. The recovery process of the open bone, inflammation reduction, and halitosis is significantly faster in PGRF group than in the group of the combination of butyl para-aminobenzoate and iodoform [18].

In another line, a different result appears in another article [14]. It reveals that the combination between butyl para-aminobenzoate and iodoform has slow action in reducing the swollen lymph node and redness around the gingiva and halitosis.

\section{Conclusion}

All articles reviewed identified pain reduction after treatment as an indicator of success. About this, four articles [6], [15], [16], [17] did not conduct a hearing 
assessment. In terms of the average of time in pain reduction, the combination of butyl para-aminobenzoate and iodoform started to reduce the pain faster than the chlorhexidine digluconate gel and the combination between polymyxin B sulfate, tyrothricin, neomycin sulfate, and tetracaine hydrochloride. Furthermore, the combination of butyl para-aminobenzoate and iodoform is also better in pain reduction compared to low-power red laser and low-power infrared laser on the first $6^{\text {th }} \mathrm{h}$ and the $12^{\text {th }} \mathrm{h}$ of observation on the $1^{\text {st }}$ day and on the first $6^{\text {th }} \mathrm{h}$ on the $2^{\text {nd }}$ day.

Another result revealed that there was no difference in terms of pain reduction between the group of the combination between butyl para-aminobenzoate and iodoform, and the group of freeze-dried pledget containing acemannan hydrogel and the provision of Er:Cr:YSGG radiation. Pain reduction using hyaluronic acid, with or without aminocaproic acid, and diode laser on the observation of the $3^{\text {rd }}, 4^{\text {th }}$, and $5^{\text {th }}$ day showed a better result than the one with the combination between butyl para-aminobenzoate and iodoform. Meanwhile, the treatment using polymyxin B sulfate, tyrothricin, neomycin sulfate, and tetracaine hydrochloride needed shorter time to relieve the whole pain than the one using the combination of butyl para-aminobenzoate and iodoform.

In another line, the treatment using hyaluronic acid with or without aminocaproic acid, low-power red laser, and low-power infrared laser on the first $12 \mathrm{~h}$ observation on the $2^{\text {nd }}$ and $3^{\text {rd }}$ day, and the treatment using low-level laser therapy on the $3^{\text {rd }}$ and $11^{\text {th }}$ day observation showed a better result in pain control and healing process than the one using the combination between butyl para-aminobenzoate and iodoform.

Besides that, in terms of time indicators and complications, the result of the healing of alveolar mucosa was better in the group of the combination of butyl para-aminobenzoate and iodoform than a group of ZOE. The healing process of the socket with the treatment using polymyxin B sulfate, tyrothricin, neomycin sulfate, tetracaine hydrochloride, diode laser, PRGF, low-level laser therapy, and freeze-dried pledget containing acemannan hydrogel showed better results than the one using the combination between butyl para-aminobenzoate and iodoform. Besides, alveolar mucosal healing process with treatment using Er:Cr:YSGG laser showed a better result, but it did not show any significant differences compared to others.

\section{References}

1. Burgoyne CC, Giglio JA, Reese SE, Sima AP, Laskin DM. The efficacy of a topical anesthetic gel in the relief of pain associated with localized alveolar osteitis. J Oral Maxillofac Surg. 2010;68(1):144-8. https://doi.org/10.1016/j. joms.2009.06.033

PMid:20006169

2. Cardoso $\mathrm{CL}$, Rodrigues MT, Ferreira Júnior $\mathrm{O}$, Garlet $\mathrm{GP}$ de Carvalho PS. Clinical concepts of dry socket. J Oral Maxillofac Surg. 2010;68(8):1922-32. https://doi.org/10.1016/j. joms.2009.09.085

PMid:20537783

3. Sekhar $\mathrm{CH}$, Narayanan $\mathrm{V}$, Baig MF. Role of antimicrobials in third molar surgery: Prospective, double blind, randomized, placebo-controlled clinical study. $\mathrm{Br} \mathrm{J}$ Oral Maxillofac Surg. 2001;39(2):134-7. https://doi.org/10.1054/bjom.2000.0557 PMid:11286448

4. Bowe DC, Rogers S, Stassen LF. The management of dry socket/alveolar osteitis. J Ir Dent Assoc. 2011;57(6):305-10. PMid:22338284

5. Noroozi AR, Philbert RF. Modern concepts in understanding and management of the "dry socket" syndrome: Comprehensive review of the literature. Oral Surg Oral Med Oral Pathol Oral Radiol Endod. 2009;107(1):30-5. https://doi.org/10.1016/j. tripleo.2008.05.043

PMid: 18755610

6. Kolokythas A, Olech E, Miloro M. Alveolar osteitis: A comprehensive review of concepts and controversies. Int J Dent. 2010;2010:249073. https://doi.org/10.1155/2010/249073 PMid:20652078

7. Cardoso CL, Ferreira Júnior O, Carvalho PS, Dionísio TJ, Cestari TM, Garlet GP. Experimental dry socket: Microscopic and molecular evaluation of two treatment modalities. Acta Cir Bras. 2011;26(5):365-72. https://doi.org/10.1590/ s0102-86502011000500007

PMid:21952659

8. de Carvalho PS, Mariano RC, Okamoto T. Treatment of fibrinolytic alveolitis with rifamycin B diethylamide associated with gelfoam: A histological study. Braz Dent J. 1997;8(1):3-8. PMid:9485630

9. Blum IR. Contemporary view on dry socket (alveolar osteitis): A clinical appraisal of standardization, aetiopathogenesis and management: A critical review. Int J Oral Maxillofac Surg. 2002;31(3):309-17. https://doi.org/10.1054/ijom.2002.0263 PMid:12190139

10. Navas RM, Mendoza MG. Case report: Late complication of a dry socket treatment. Int J Dent. 2010;2010:479306. https://doi. org/10.1155/2010/479306

PMid:21253516

11. Zuniga JR, Leist JC. Topical tetracycline-induced neuritis: A case report. J Oral Maxillofac Surg. 1995;53(2):196-9. https:// doi.org/10.1016/0278-2391(95)90402-6 PMid:7830188

12. Moore JW, Brekke JH. Foreign body giant cell reaction related to placement of tetracycline-treated polylactic acid: Report of 18 cases. J Oral Maxillofac Surg. 1990;48(8):808-12. https://doi. org/10.1016/0278-2391(90)90338-3 PMid:2197383

13. Syrjänen S, Syrjänen K. Influence of Alvogyl on the healing of extraction wound in man. Int J Oral Surg. 1979;8:22-30. https:// doi.org/10.1016/s0300-9785(79)80035-6

PMid:107131

14. King EM, Cerajewska TL, Locke M, Claydon NC, Davies M, West NX. The efficacy of plasma rich in growth factors for the treatment of alveolar osteitis: A randomized controlled trial. J Oral Maxillofac Surg. 2018;76(6):1150-9. https://doi. org/10.1016/j.joms.2017.12.025

PMid:29382467

15. Eshghpour M, Ahrari F, Najjarkar NT, Khajavi MA. Comparison 
of the effect of low level laser therapy with alvogyl on the management of alveolar osteitis. Med Oral Patol Oral Cir Bucal. 2015;20(3):e386-92. https://doi.org/10.4317/medoral.2037

PMid:25662557

16. Kaya GŞ, Yapici G, Savaş Z, Güngörmüş M. Comparison of alvogyl, salicept patch, and low-level laser therapy in the management of alveolar osteitis. J Oral Maxillofac Surg. 2011;69(6):1571-7. https://doi.org/10.1016/j.joms.2010.11.005 PMid:21398006

17. Rani A, Mohanty S, Sharma P, Dabas J. Comparative evaluation of Er:Cr:YSGG, diode laser and alvogyl in the management of alveolar osteitis: A prospective randomized clinical study. J Maxillofac Oral Surg. 2016;15(3):349-54. https://doi. org/10.1007/s12663-015-0848-4

PMid:27752206

18. Faizel S, Thomas S, Yuvaraj V, Prabhu S, Tripathi G. Comparision between neocone, alvogyl and zinc oxide eugenol packing for the treatment of dry socket: A double blind randomised control trial. J Maxillofac Oral Surg. 2015;14(2):312-20. https://doi. org/10.1007/s12663-014-0667-z

PMid:26028852

19. Supe NB, Choudhary SH, Yamyar SM, Patil KS, Choudhary AM, Kadam VD. Efficacy of alvogyl (combination of iodoform+butylparaminobenzoate) and zinc oxide eugenol for dry socket. Ann Maxillofac Surg. 2018;8(2):193-9. https://doi. org/10.4103/ams.ams_167_18

PMid:30693231

20. Taberner-Vallverdú M, Nazir M, Sánchez-Garcés MÁ, Gay-Escoda C. Efficacy of different methods used for dry socket management: A systematic review. Med Oral Patol Oral Cir Bucal. 2015;20(5):e633-9. https://doi.org/10.4317/medoral.20589

PMid:26116842 